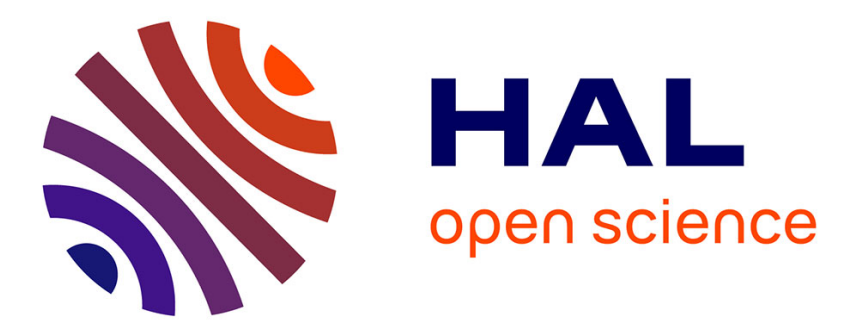

\title{
An Experimental Investigation into the Deployment of 3D, Finned Wing and Shape Memory Alloy Vortex Generators in a Forced Air Convection Heat Pipe Fin Stack
}

\author{
M.S. Aris, R. Mcglen, I. Owen, C.J. Sutcliffe
}

\section{To cite this version:}

M.S. Aris, R. Mcglen, I. Owen, C.J. Sutcliffe. An Experimental Investigation into the Deployment of 3D, Finned Wing and Shape Memory Alloy Vortex Generators in a Forced Air Convection Heat Pipe Fin Stack. Applied Thermal Engineering, 2011, 31 (14-15), pp.2230. 10.1016/j.applthermaleng.2011.03.015 . hal-00781348

\section{HAL Id: hal-00781348 \\ https://hal.science/hal-00781348}

Submitted on 26 Jan 2013

HAL is a multi-disciplinary open access archive for the deposit and dissemination of scientific research documents, whether they are published or not. The documents may come from teaching and research institutions in France or abroad, or from public or private research centers.
L'archive ouverte pluridisciplinaire HAL, est destinée au dépôt et à la diffusion de documents scientifiques de niveau recherche, publiés ou non, émanant des établissements d'enseignement et de recherche français ou étrangers, des laboratoires publics ou privés. 


\section{Accepted Manuscript}

Title: An Experimental Investigation into the Deployment of 3D, Finned Wing and Shape Memory Alloy Vortex Generators in a Forced Air Convection Heat Pipe Fin Stack

Authors: M.S. Aris, R. McGlen, I. Owen, C.J. Sutcliffe

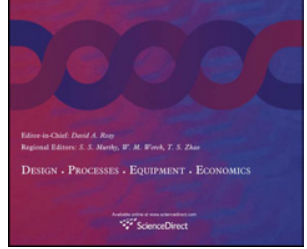

PII:

$$
\text { S1359-4311(11)00147-5 }
$$

DOI:

Reference: $\quad$ ATE 3470

To appear in: Applied Thermal Engineering

Received Date: 6 April 2010

Revised Date: 2 February 2011

Accepted Date: 11 March 2011

Please cite this article as: M.S. Aris, R. McGlen, I. Owen, C.J. Sutcliffe. An Experimental Investigation into the Deployment of 3D, Finned Wing and Shape Memory Alloy Vortex Generators in a Forced Air Convection Heat Pipe Fin Stack, Applied Thermal Engineering (2011), doi: 10.1016/ j.applthermaleng.2011.03.015

This is a PDF file of an unedited manuscript that has been accepted for publication. As a service to our customers we are providing this early version of the manuscript. The manuscript will undergo copyediting, typesetting, and review of the resulting proof before it is published in its final form. Please note that during the production process errors may be discovered which could affect the content, and all legal disclaimers that apply to the journal pertain. 


\title{
An Experimental Investigation into the Deployment of 3D, Finned Wing and Shape Memory Alloy Vortex Generators in a Forced Air Convection Heat Pipe Fin Stack
}

\author{
${ }^{1}$ M.S.Aris, ${ }^{2}$ R.M ${ }^{\mathrm{c}}$ Glen, ${ }^{3}$ I.Owen, ${ }^{3}$ C.J. Sutcliffe \\ ${ }^{1}$ Department of Mechanical Engineering, Universiti Teknologi Petronas, Bandar Sri Iskandar, 31750, \\ Malaysia \\ ${ }^{2}$ Thermacore Europe (Ltd), Ashington, NE63 8QW, United Kingdom \\ ${ }^{3}$ University of Liverpool, Brownlow Hill, Liverpool, L69 3GH, United Kingdom
}

\begin{abstract}
Forced air convection heat pipe cooling systemsplay an essential role in the thermal management of electronic and power electronic devices such as microprocessors and IGBT's(Integrated Gate Bipolar Transistors). With increasing heat dissipation from these devices, novel methods of improving the thermal performance of fin stacks attached to the heat pipe condenser section are required. The current work investigatesthe use of a wing type surface protrusions in the form of 3-D delta wing tabs adhered to the fin surface, thin wings punched out of the fin material and TiNi shape memory alloy delta wings which changed their angles of attack based on the fin surface temperature. The longitudinal vortices generated from the wing designs induce secondary mixing of the cooler free stream air entering the fin stack with the warmer fluid close to the fin surfaces. The change in angle of the attack of the active delta wings provide heat transfer enhancement while managing flow pressure losses across the fin stack. A heat transfer enhancement of $37 \%$ compared to a plain fin stack was obtained from the 3-D tabs in a staggered arrangement. The punched-out delta wings in the staggered and in-line arrangements provided enhancements of $30 \%$ and $26 \%$ respectively. Enhancements from the active delta wings were lower (16\%), however as these devicesreduce the pressure drop through the fin stack by approximately $19 \%$ in the deactivate position, over the activated position; a reduction in fan operating cost may be achieved for systems operating with inlet air temperatures below the maximum inlet temperature specification for the device. CFD analysis was also carried out to assess the local heat transfer enhancement effects. The CFD results corresponded well with previously published reports and were consistent with the experimental findings.
\end{abstract}

\section{Keywords:}


Heat pipes, vortex generators, active delta wings, heat transfer enhancement, fin stack, forced convection.

\subsection{Introduction}

Forced convection cooling of extended surfaces such as heat sinks and heat pipe fin stacks is a primary cooling technique used in microelectronic and telecommunication applications. The increasing power densities in these applications have encouraged research into heat transfer enhancement methods used to improvethe cooling capacities of their thermal management designs. The introduction of heat pipe systems hasminimised spreading resistances associated with standard heat sinks, providing a more efficient means of heat removal and addressing the issue of space constraints experienced in many thermal management applications. In a typical heat pipe system design shown in Fig. 1, the heat source is cooled by transferring heat away through a two-phase medium in the heat pipes to a condenser fin-stack. Air, as the cheapest and the most available cooling medium is then used to convectively remove heat from the fin surfaces in the condenser section. As fin-to-air heat transfer typically experiences the highest thermal resistance in the heat pipe system, an improvement in the cooling capacity of the condenser fin stack would translate to a more efficient heat pipe cooling system.

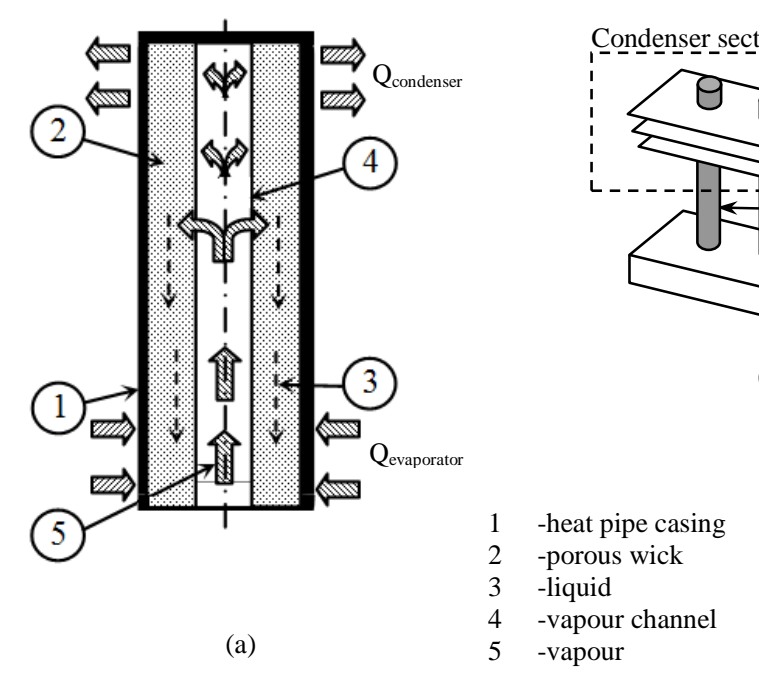

Figure 1: Heat pipe cooling system: (a) components in a conventional heat pipe and, (b) forced convection heat pipe cooling system with a fin stack 
One way of improving the cooling capacity of the condenser fin-stack is through the use of surface protrusions or turbulators. Some of the surface protrusion designs, as shown in Fig. 2, have been previously explored and reported to offer significant enhancement effects.

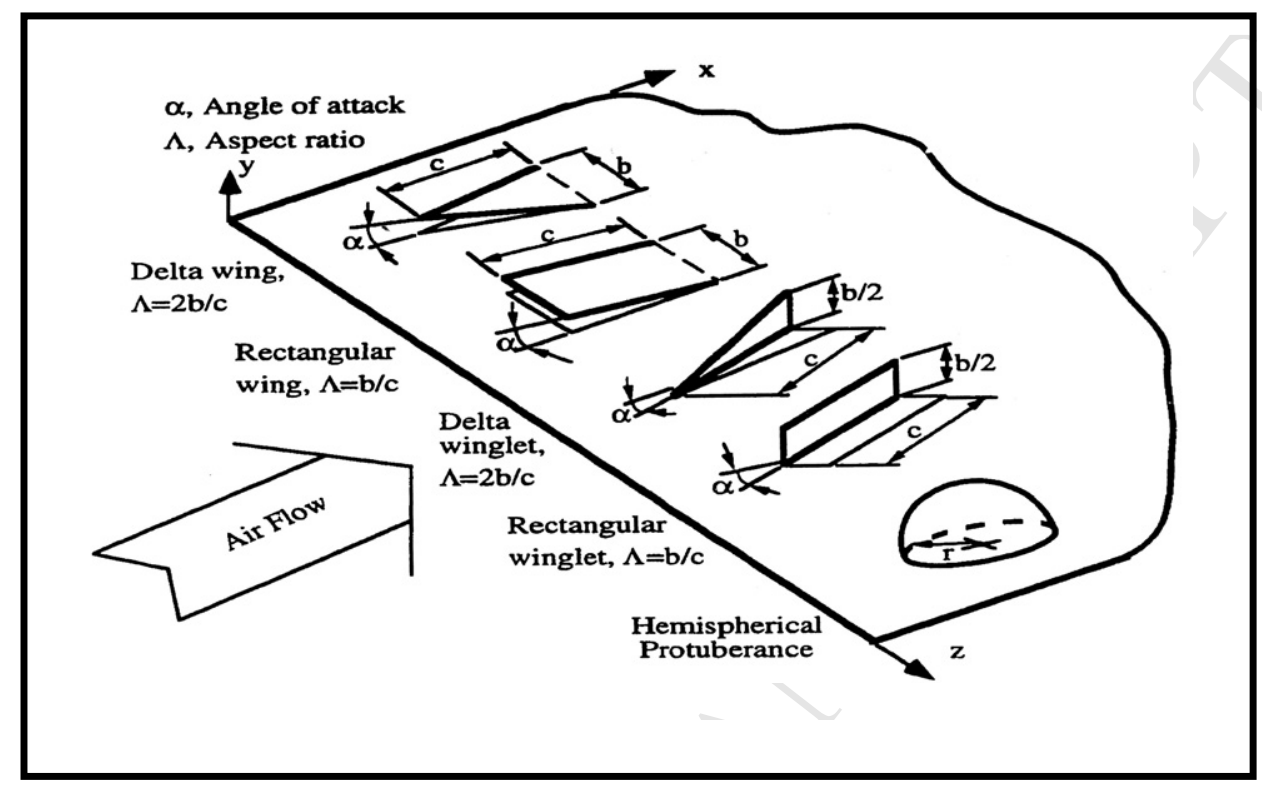

Figure 2: $\quad$ Surface protrusion designs (adapted from Jacobi and Shah, 1995)

The earliest reported research into heat transfer enhancement on flat heated surfaces was carried out by Edwards and Alker (1974) in which the effects of surface protrusions in the form of cubes and delta winglets were compared. In their research, it was found that for laminar flows over a flat surface, the cube protrusion gave high local heat transfer enhancements while the winglets, which produced longitudinal vortices, offeredrelatively longer-lasting downstream enhancements. Further studies into the heat transfer mechanisms involvingdelta and rectangular wings and winglet pairson the surfaces of fins-stacks were later explored by Fiebig (1986). The enhancement mechanism was related to the observed swirling action of the vortices in the downstream areas of the vortex generators (VG), where the mixing of cooler free stream flow with the warmer air just above the fin surface took place. The enhancement effects were also found to increase with vortex strength; a quantity which increases with the wing or winglet's angle of attack, aspect ratio and the fluid flow Reynolds number. In comparing the enhancement effects of the various VG designs, it was found that the longitudinal vortices generated by delta wings were far more effective at heat transfer enhancement for a given fin and VG area. Table 1 
summarizes the results from Fiebig's study with respect to the Colburn- $j$ factor per unit area, $\Delta j / \mathrm{mm}^{2}$ at a Reynolds number of 1815 , based on the fin stack spacing and for an angle of attack, $\alpha=30^{\circ}$.

Table 1: Heat transfer enhancement from various surface protrusion designs (adaptedfrom Fiebig et al., 1986)

\begin{tabular}{|c|c|c|}
\hline Surface protrusion design & $\begin{array}{l}\text { Vortex generator and fin surface area } \\
\qquad\left(\mathrm{mm}^{2}\right)\end{array}$ & $\begin{array}{c}\text { Colburn- } j \text { factor/area } \\
\qquad\left(1 / \mathrm{mm}^{2}\right)\end{array}$ \\
\hline Delta wing & 500 & 0.0026 \\
\hline Delta winglet pair & 800 & 0.00175 \\
\hline Rectangular wing & 1000 & 0.0015 \\
\hline Rectangular winglet pair & 1600 & 0.0012 \\
\hline
\end{tabular}

Fiebig et al. (1991) continued to study the enhancement effects from the list of VG samples in their earlier work, with emphasis on determining drag coefficients and theinfluence of angle of attack and aspect ratios. In their investigation, the drag induced by the VGs was found to be independent of Reynolds number and VG geometry, but proportional to VG area, and increased with angle of attack. The heat transfer enhancement effects, as expected, were found to increase with Reynolds number, aspect ratio and angle of attack. For an increase in aspect ratios, from $\Lambda=$ 0.8 to 1.5 and angles of attack, from $\alpha=20$ to $40^{\circ}$, the average enhancement effects rose by $25 \%$.

A practical considerationin the application of delta wing VGs is their mounting details on the fin surfaces and how it influencesthe downstream vortex strength. Biswas and Chattopadhyay (1992), carried out a numerical prediction on the enhancement effects and flow pressure losses for a thin VG which was either adhered to or punched-out-of, a fin surface. From their investigation, the VG adheredto the fin surface was found to produce higher heat transfer enhancements andthe difference in average enhancements between the two mounting types increased with Reynolds number. The numerically predicted vortex magnitudes show a stronger presence for anadheredVG as opposed to weaker vortices due to losses through the hole underneath the punchedout VGs. In terms of comparing the flow pressure losses with and without the VGs, the punched-out VGs were favourable with results of a $45 \%$ increase as compared to a $78 \%$ increase for the VGs that were adhered to the fin surface. 
For fin stacks, Gentry et al. (2002)measured the vortex strength at downstream locations of single VGs, which wereadhered to theleading edge of the fin surfaces. The authors concluded, from their study, thatthe vortices were effectively cooling alonger downstream distance along the fin surfaces in the stack as compared to a VG on anun-bounded fin. One reason given for the prolonged cooling effect was the ability of the adjacent fins in keeping the secondary mixingcloser to the fin surfaces. It was also suggested that VGs in a fin stack adopthigher angles of attack (larger than $55^{\circ}$, as reported by Gentry, 2002) to increase heat transfer enhancements as the fin channels in the fin stack has the ability to prevent the occurrence of "vortex breakdown".

For studies involving a pair or an array of VGs, the additional parameters which would be of concernare the effects of the spanwise and streamwise spacing as shown in Fig.3. Pauley and Eaton (1994) reported on the effects of delta wing and winglet VG spacing for turbulent flow conditions and recommended a minimum spacing of two wing widths between VG centres. The investigators claimed that a closer VG spacing would slightly inhibit the ability of the VGs to generate effective longitudinal vortices. For developing flows, Aris et al. (2008) explored the effects of VG spacing for a pair of rectangular wings and found that at approximately one wing width spacing between their centres, significant enhancement coverage was obtained for the downstream areas, extending to $90 \%$ of the test section length.

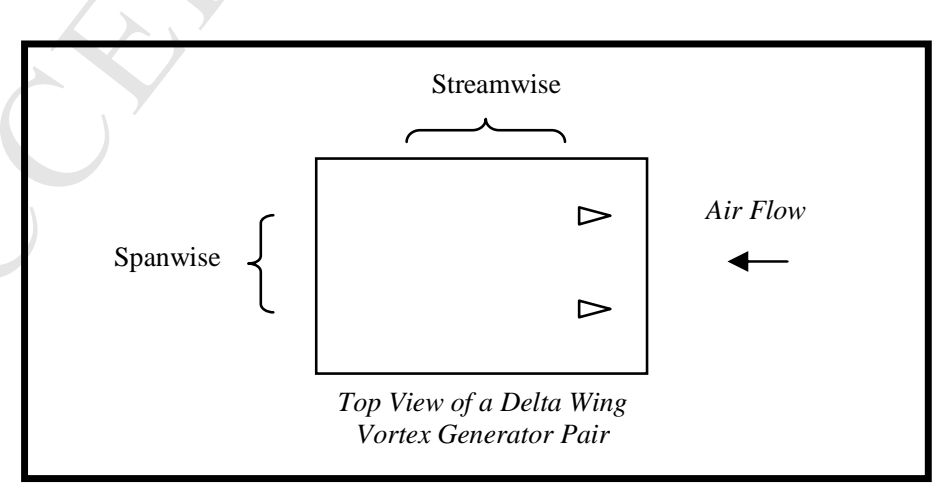

Figure 3: $\quad$ Streamwise and spanwise spacing of delta wing vortex generators on a flat surface

In further efforts to explore the effects of different VG designs, Liou et al. (2000)showed that the delta wing VG design could produce higher heat transfer enhancements if the front portion connecting its tip to the base was fully covered to 
form a solid body as shown in Fig. 4. Heat transfer enhancements were approximately $50 \%$ higher than the uncovered VG and the pressure loss was eight times less for the covered VG when tested under turbulent flow conditions. The direction of air flow past a covered VG, as shown in Fig. 5(a), eliminates the high pressure drop region beneath the vortex generator providing a larger pressure head that result in an increased mass flow rate and more effective vortices.

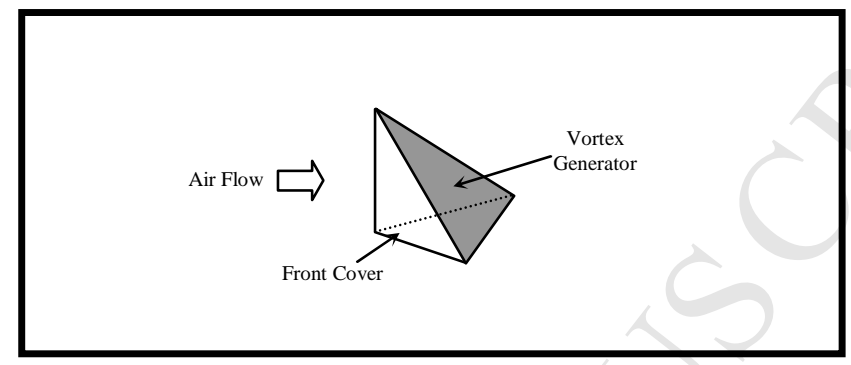

Figure 4: $\quad 3-D$ Delta Wing Vortex Generator

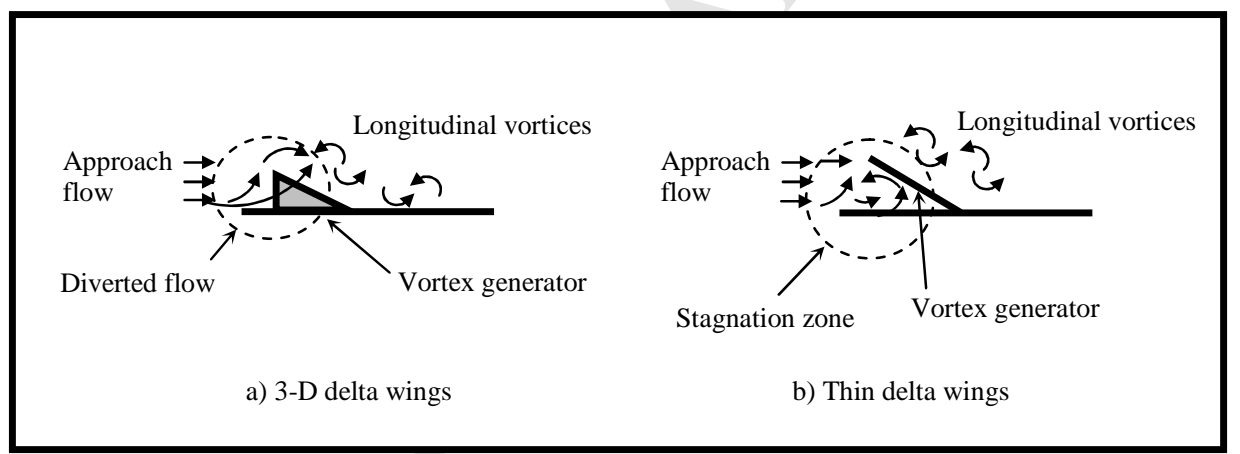

Figure 5: $\quad$ Flow past a thin Vortex Generator and a 3-D delta wing tab

One issue reported in the majority of the VG investigations is the high flow pressure losses due the high angles of attack and aspect ratio of the wings. In order to find a solution to this issue, Aris et al. (2007)explored the use of active delta wing VGs made from shape memory alloys. The TiNi shape memory alloy material featured a metallurgical diffusionless shape transformation characteristic which is induced by changes in the material temperature. The active VGsin Aris' research were manufactured in a selective laser melting (SLM) process and responded to high and low temperature set points by changing their angles of attack from $20^{\circ}$ to $35^{\circ}$. The features demonstrated by the active VGs displayed great potential in managing the high flow pressure losses associated with VG angles of attack. In industrial 
applications, the shape memory alloy VGs' features of maintaining a low pressure drop at lower operational temperatures are beneficial in terms of reducing fan operating cost, extending the fan life, as well as the reduction in the total cost of ownership of the system due to reduced energy usage.

In heat transfer enhancement investigations for full scale heat exchangers, Elsherbini and Jacobi (2002) applied delta wings on the leading edge of the fin surfaces of a refrigerator evaporator. The wings were placed on alternative fin surfaces in the evaporator fin stack. Sommers and Jacobi (2005) later continued the experiment to explore the effects of a delta wing array arrangement on all the fin surfaces in the fin stack. In general, the experiments found thatthe performance of the refrigerator evaporator increased with the use of the delta wing vortex generators. In comparison with a plain fin surface, the performance increase based on the Colburn- $j$ factor were $31 \%$ in Elsherbini and Jacobi (2002) and as high as 120\% in Sommers and Jacobi (2005).

The application of delta wing vortex generators for the condenser fin stack considered in the current work is believed to bring about similar benefits as found forthe various VG designs and test conditions explored in previous studies. As such, an experimental investigation of several delta wing designs and arrangements for a heat pipe condenser fin stack have been carried out in the present investigation. In addition to the experiments, acomputational fluids dynamic (CFD) study was carried out to provide a quantitative assessment of the enhancement effects at specific locations in the fin stack which was not accessible in the experiments and a qualitative description of the vortex path and its cooling effects on the fin surfaces.

\section{Experimental Study}

\subsection{Vortex Generator Designs}

Heat transfer enhancement experiments were initially carried out for two different fixed delta wing designs; thin delta wings and 3-D delta wing tabs. The thin delta wings were punched out of the fin surfaces while the 3-D wings were adhered to the fin surface. Further information on the effects of punched holes and delta wing 
designs can be found in Biswas and Chattopadhyay (1992) and Liou et al. (2000). Results from the initial fixed VG experiments provided guidelines, mainly in the best possible VG arrangements, and were used to explore the capabilities of active VGs. Based on these results, the array arrangement of shape memory alloy delta wings were selected, adhered to the fin surfaces and tested to observe how the heat transfer coefficient and flow pressure losses were affected. The fixed and active VG designs explored in the current work are illustrated in Fig. 6 .

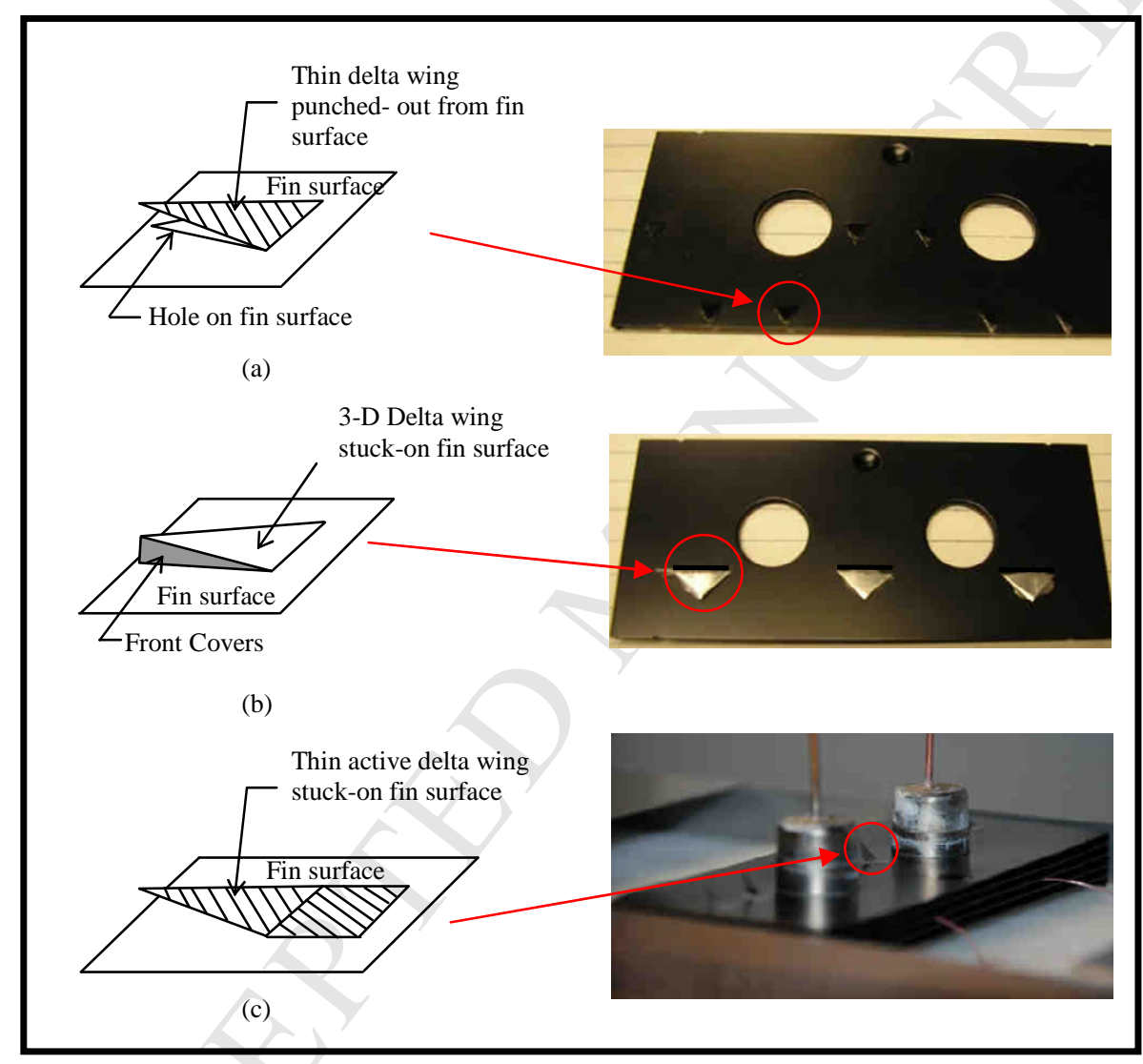

Figure 6 Fixed and active delta wing vortex generator designs

The punched-out wings were formed at an angle, $\alpha=30^{\circ}$ to the fin surface and had an aspect ratio, $\Lambda=2$. The $3-\mathrm{D}$ wings were machined into shape from solid aluminium pieces with $\alpha=14^{\circ}$ and $\Lambda=4$. The geometrical features of the fixed delta wings were based on recommendations found in previous investigations. For the active VG's, thin sheets of TiNi shape memory alloy material procured from Memry GmbH were cut into delta wing shapes, with an aspect ratio, $\Lambda=2$. Additional shape memory alloy preparation procedures are required before the active VGs could respond to their 
temperature set-points. Further details on the active VG preparation procedures are discussed in the next section.

The appropriate location of the fixed and active VGs on the fin surface dependson the flow condition in the fin-stack channels. It is important, as pointed out in the findings of Jacobi and Shah (1995) and Gentry et al. (2002) that the VG tip remains above the boundary layer height to generate vortices of reasonable quality and which are maintained throughout a long downstream distance. In the majority of fin-stack designs, the fin experiences developing flow conditions throughout most of its length and it is preferable for the VGsto be located close to the leading edge for certainty that the vorticesare generated above the boundary layer height. However, the vortices from a delta wing have been known to follow a narrow downstream path, limiting theirspanwise enhancement effects. A strategic downstream wing location is therefore necessaryforthe enhancements to cover a much larger area and improve overall heat transfer enhancement effects. The VG arrangements explored in the current experiment were chosen to maximise enhancement coverage and are shown in Fig. 7. 


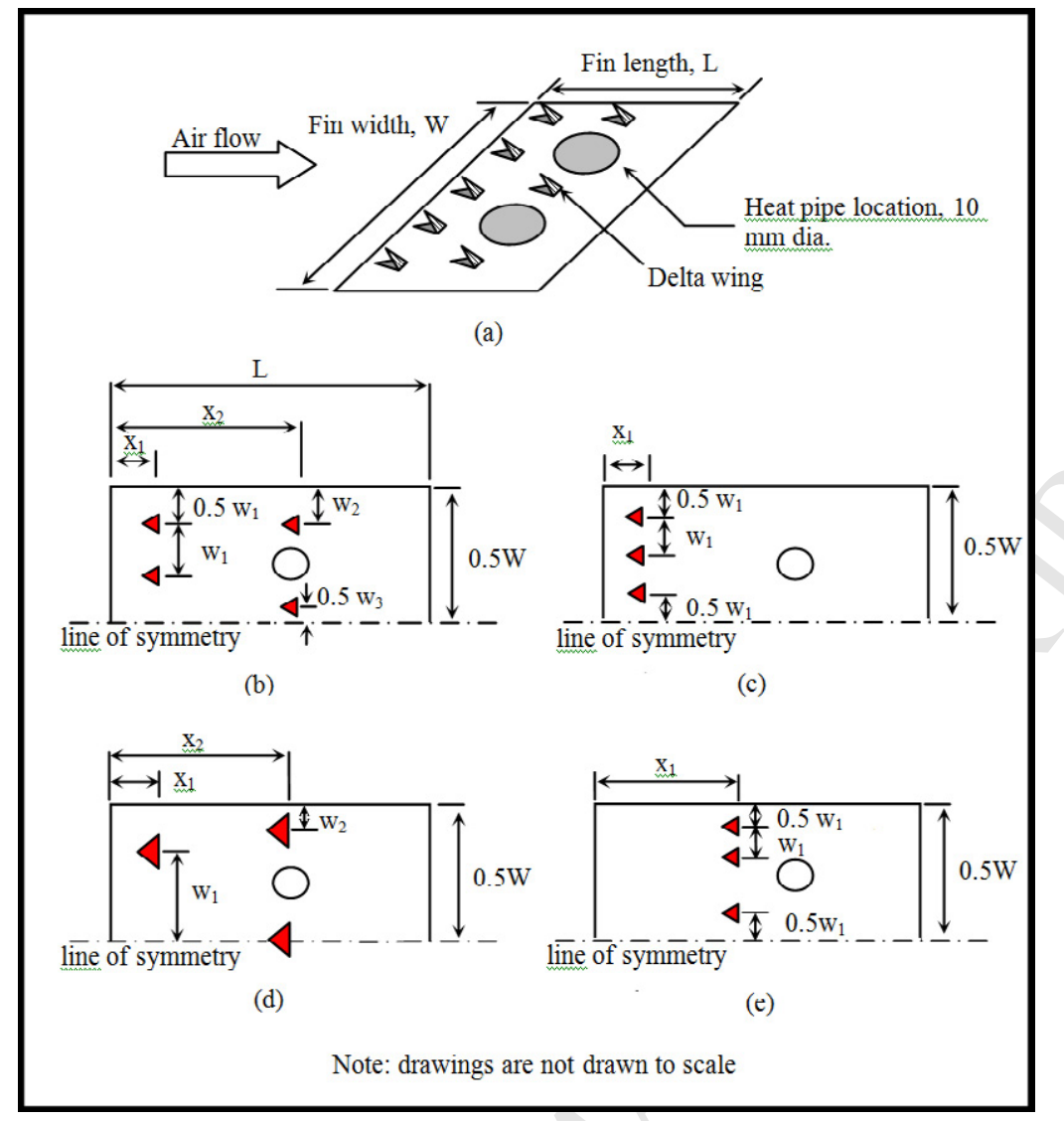

Figure 7: (a) Full width and length of fin, (b) punched-out wings in a staggered arrangement, (c)punched-out wings in an inline arrangement, (d) 3-D wings in a staggered arrangement and, (e) active wings in an in-line arrangement.

\subsection{Active Vortex Generators}

The active VGs made from TiNi can be trained to respond to temperature changes in a metallurgical diffusionless phase transformation process. The training procedure to acquire the two-way shape memory effectsets in a high and low reference temperaturewhich the material recognises and responds to during normal operation;this temperature is also known as the "activation" or "deactivation" temperature of the vortex generator. In an industrial application, the activationtemperature may be set just below the thermal limits of a plain fin to ensure continuous cooling.

Details of the phase transformation process and the two-way shape memory effect training for active delta wings have been reported in Aris et al. (2007). In the current work, the thin sheets of TiNi were first heat treated at $620^{\circ} \mathrm{C}$ in a furnace to set-in 
their active shapes. The active VGs were then two-way trainedusing a martensite deformation technique suggested by Lahoz et al. (2002) and illustratedin Fig. 8. In the training procedure, the training jig was designed to constrain the sample at an angle of $5^{\circ}$ below horizontal to take into account losses from the permanent deformation of the sample.

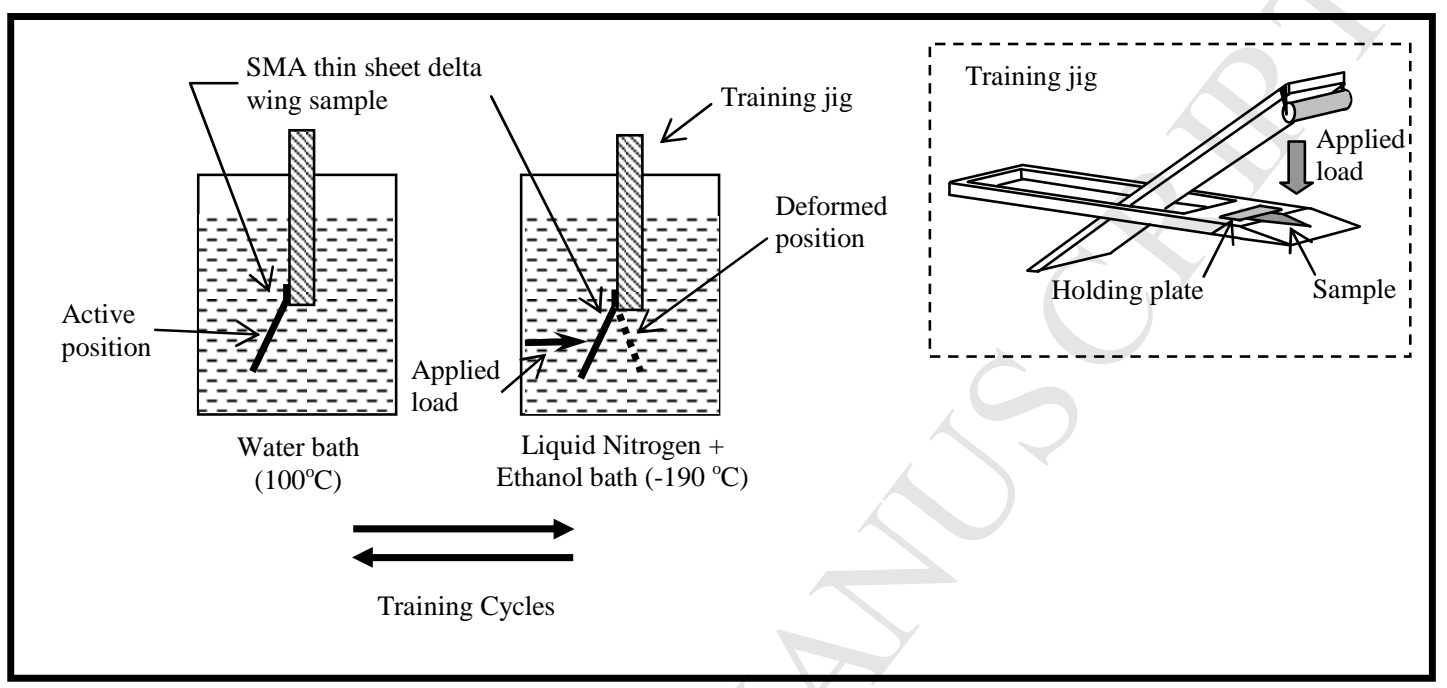

Figure 8: Training cycle procedure for the shape memory alloy delta wings. Insert: training jig

As a result of the two-way training, the VGs responded to a high temperature set point of $65^{\circ} \mathrm{C}$ by increasing their angles of attack, initially from $0^{\circ}$ to $45^{\circ}$. At room temperature, the VGs de-activate to a low angle of attack (approximately $0^{\circ}$ ). However, the numerous training cycles and external effects during their installation on the fin surfaces resulted in losses in the activation and de-activation angles and the working angles of attack, measured after the VGs were mounted on the fin surfaces were found to be $30^{\circ}$ (active) and $5^{\circ}$ (de-activated).

\subsection{Heat Transfer and Flow Pressure Loss Experimental Set-up}

The experimental work to investigate the heat transfer enhancement and flow pressure losses from a condenser fin stack was carried out in an air flow rig (flow bench wind tunnel) consisting of a test section, inlet and outlet ducts, sensors and instrumentation for data acquisition. The heat pipe condenser fin stack was represented by a set of five fins and two heat pipes which was supplied with a constant heating power of $60 \mathrm{Watts}$ 
through a heated copper block,attached to the heat pipe base. A schematic of the experimental set up is shown in Fig. 9.

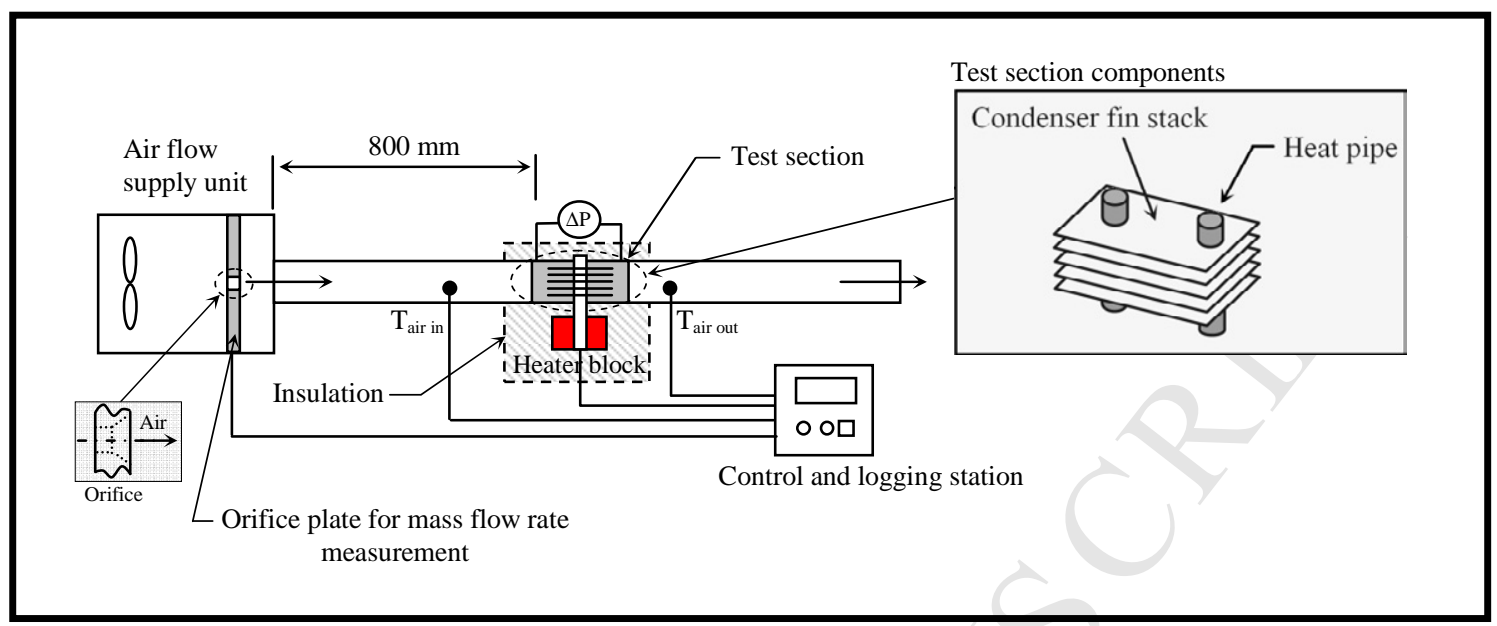

Figure 9: Experimental set-up to explore heat transfer enhancements and flow pressure loss from a condenser fin stack

Air was supplied from a fan and directed to flow into the test section through a $10 \mathrm{~mm}$ (high) x 50mm (wide) x 800mm (long) rectangular cross section duct. The Reynolds number, $\mathrm{Re}_{\mathrm{H}}$ for the experiment was based on the channel height, $\mathrm{H}$ of the air supply duct with a range of 330to 960. The mass flow rate in the air flow test rig was determined from an orifice unit located after the fan in the air flow supply section and checked with a hand held anemometer close to the exit duct. The air inlet and outlet temperatures were measured by T-type thermocouples placed at the locations before and after the test section.

The overallheat transfer enhancement from the fin stack was determined from the heat transfer enhancement ratio,

$$
\frac{\mathrm{Q}}{\mathrm{Q}_{0}}=\frac{\dot{\mathrm{m}} \mathrm{vG}_{\mathrm{p}, \mathrm{vg}}\left(\mathrm{T}_{\mathrm{in}, \mathrm{vG}}-\mathrm{T}_{\text {out } \mathrm{vG}}\right)}{\dot{\mathrm{m}{ }_{\mathrm{C}} \mathrm{C}_{\mathrm{p}, \mathrm{o}}\left(\mathrm{T}_{\mathrm{in}, 0}-\mathrm{T}_{\text {out }, 0}\right)}}
$$

Equation 1

The flow pressure loss across the test section was represented the Darcy friction factor ratio, $f / f_{0}$,calculated from the measured static pressure drop across the test section.

$$
\frac{\mathrm{f}}{\mathrm{f}_{0}}=\frac{\Delta \mathrm{P}_{\mathrm{vc}} \rho_{0} \mathrm{~V}_{\mathrm{o}, \text { avg }}{ }^{2}}{\Delta \mathrm{P}_{0} \rho_{\mathrm{vG}} \mathrm{V}_{\mathrm{VGavg}}{ }^{2}}
$$


The friction factor ratio is used in the majority of relevant, previous investigations, therefore is useful to allow comparisons to be made with the results from the current work. The properties of air in the above equations were evaluated at the average air temperature across the test section, $\mathrm{T}_{\text {mean }}$.

\subsection{Experimental uncertainties}

Uncertainties in the experimentalmeasurements were determined with a confidence level of $95 \%$ for the variables in Eq. (1) and (2). The worst case of uncertainties in the air temperature, mass flow rate and flow pressure loss measurements were $+/-2 \%,+/$ $11 \%$ and $12 \%$ of their respective mean values. The error propagation into the heat transfer enhancement ratio calculations was determined from the Kline and McClintock's $2^{\text {nd }}$ Power Law (Kline and McClintock, 1953) where the highest uncertainty was found to be within $+/-7 \%$ of the mean value for the staggered, punched-out VG sample at $\mathrm{Re}_{\mathrm{H}}=330$.

\subsection{Numerical Simulation}

The numerical model solution domain is illustrated in Fig. 10. The shape and sizes of the cells specified in the solution domain were based on the geometric details and critical heat transfer enhancement locations. A grid independence exercise was also carried out to determine the appropriate number of cells to be used in the solution domain. 


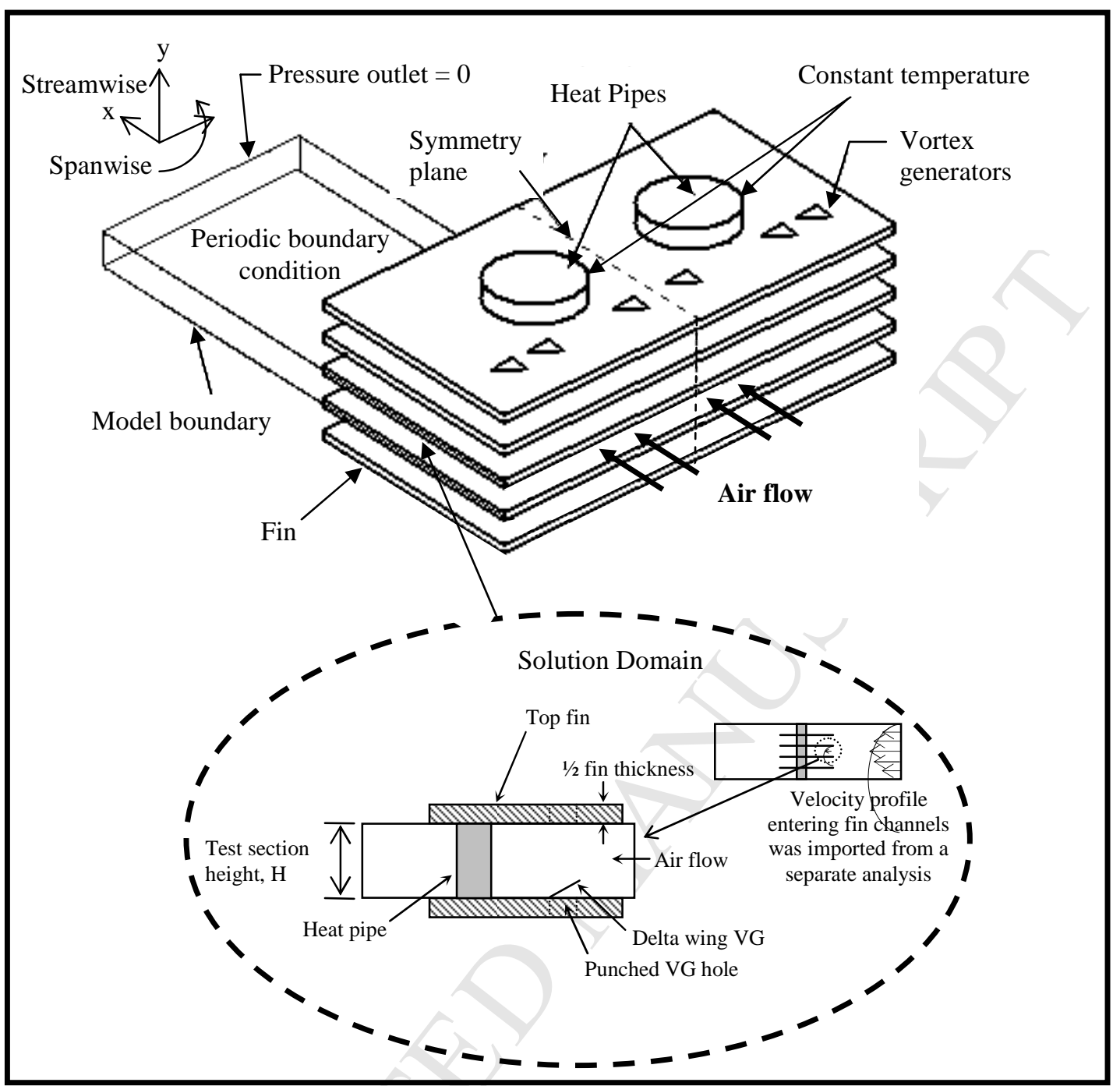

Figure 10: CFD model boundary on a vortex generator fin stack

Due to the lack of appropriate experimental data, the validation of the current CFD results was carried out by comparing them with the results of a numerical study by Biswas and Chattopadhyay (1992) for a plain test section, a single delta wing VG punched out of the test section and a single delta wing VG mounted on the test section surface, at $\mathrm{Re}_{\mathrm{H}}=300$. For similar boundary conditions, the spanwise average Nusselt numbers, $\mathrm{Nu}_{\mathrm{sa}}$, for each model were compared along the streamwise distance based on the test section height, $\mathrm{x} / \mathrm{H}$, as shown in Fig.11. 


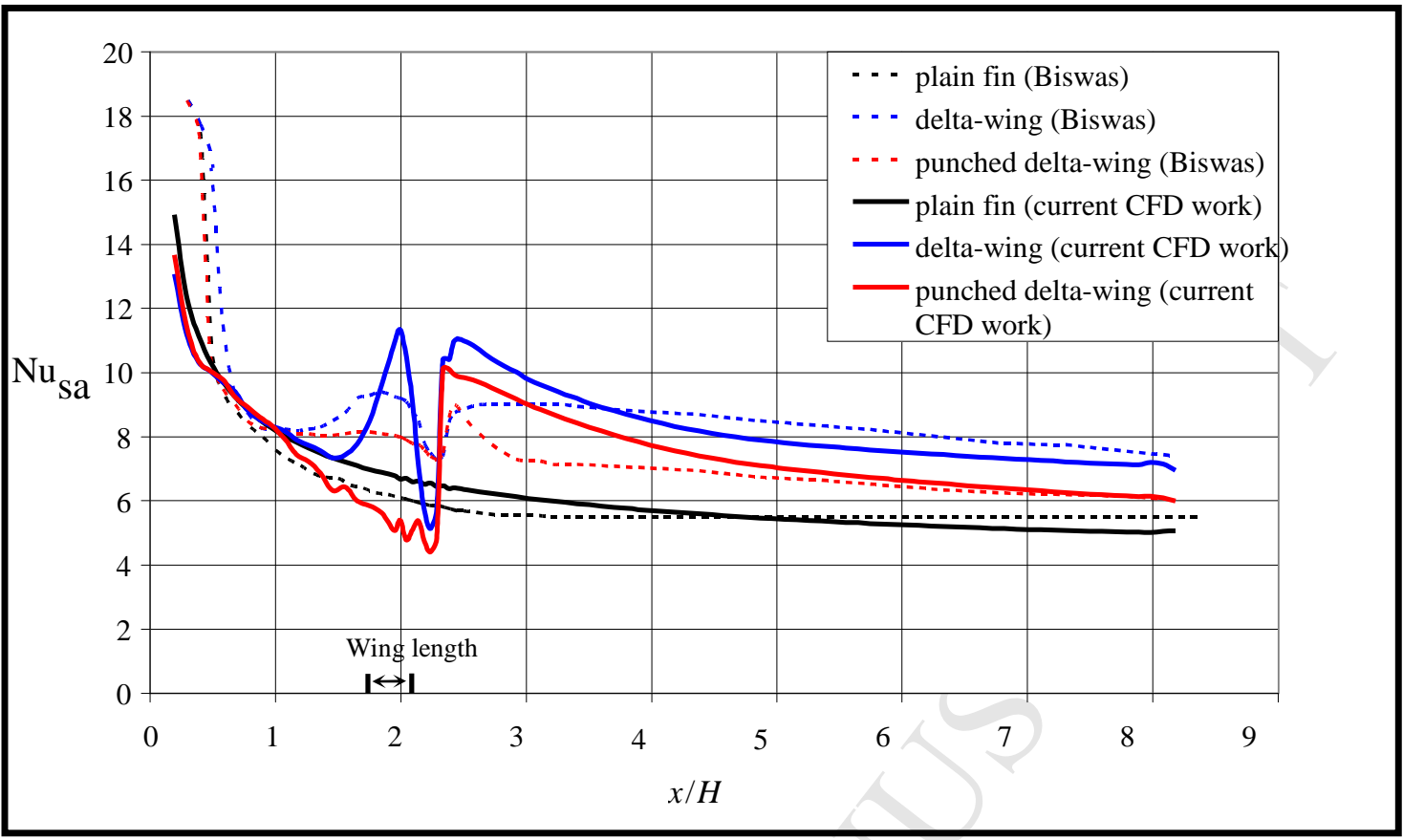

Figure 11: Comparison of the spanwise average Nusselt numbers of the current CFD model with the work of Biswas and Chattopadhyay (1992)

The difference in the spanwise average Nusselt numbers for the two studies varied along the test section surface. A reasonable agreement was achieved for the plain test section where differences of between 0 and $8 \%$ were observed for the current CFD model and results reported by Biswas. Comparing the single delta wing, with and without the punched holes, higher differences at the test section leading edge and at a region immediately downstream of the delta wing was observed. Reasonable agreement, however, was observed at the upstream region of the delta wing and for downstream distances of $\mathrm{x} / \mathrm{H}=3.5$, onwards.

Although the quantitative values from the current CFD models are clearly different at certain locations, the results can still be used as an indication of the heat transfer trends. Overall, the spanwise average Nusselt numbers from both studies showed similar trends along the streamwise direction of the test section surface, with expected peaks at the leading edge, a drop in the stagnant area in the immediate neighbourhood behind the middle of the wing-body junction, a peak at the one chord-length distance downstream of the VG and a gradual decrease towards the tail end of the test section 


\subsection{Results and Discussions}

\subsection{Experimental Results}

The enhancement effects on the fin-stack test section from applying the VG designs and arrangementis clearly shown in the experimental results. Table 2 list the VG locations while the heat transfer enhancements, flow pressure loses and the $\mathrm{Re}_{\mathrm{H}}$ for the respective VG designs are given in Table 3.

Table 2: $\quad$ Selected vortex generator designs and arrangements

\begin{tabular}{|c|c|c|c|c|c|c|c|}
\hline \multirow[b]{2}{*}{ VG Designs } & \multicolumn{7}{|c|}{ Location Details } \\
\hline & Arrangement & Sample Ref. & $\mathrm{x}_{1} / \mathrm{L}$ & $\mathrm{x}_{2} / \mathrm{L}$ & $\mathrm{w}_{1} / \mathrm{W}$ & $\mathrm{w}_{2} / \mathrm{W}$ & $\mathrm{w}_{3} / \mathrm{W}$ \\
\hline \multirow[t]{2}{*}{ 3-D delta wings } & \multirow[b]{2}{*}{ Staggered } & SN1 & 0.2 & 0.3 & 0.48 & 0.125 & - \\
\hline & & SN2 & 0.3 & 0.5 & 0.48 & 0.125 & - \\
\hline \multirow{6}{*}{ Thin delta wings } & \multirow{2}{*}{ Staggered } & SN3 & 0.1 & 0.5 & 0.3 & $0 . .075$ & 0.15 \\
\hline & & SN4 & 0.2 & 0.5 & 0.3 & 0.075 & 0.15 \\
\hline & \multirow{4}{*}{ Inline } & SN5 & 0.1 & - & 0.3 & - & - \\
\hline & & SN6 & 0.2 & - & 0.3 & - & - \\
\hline & & SN7 & 0.1 & - & 0.5 & - & - \\
\hline & & SN8 & 0.2 & - & 0.5 & - & - \\
\hline Active delta wings & Inline & SN9 & 0.4 & & 0.3 & - & - \\
\hline
\end{tabular}

Table 3: Heat transfer and friction factor results for selected vortex generator designs and arrangements

\begin{tabular}{|c|c|c|c|c|c|c|c|}
\hline \multirow{2}{*}{ VG Designs } & \multirow{2}{*}{ Sample Ref. } & \multicolumn{3}{|c|}{$\mathrm{Q} / \mathbf{Q}_{0}$} & \multicolumn{3}{|c|}{$f / f_{o}$} \\
\hline & & $\mathrm{Re}=330$ & $\mathrm{Re}=730$ & $\operatorname{Re}=960$ & $\mathrm{Re}=330$ & $\mathrm{Re}=730$ & $\mathrm{Re}=960$ \\
\hline \multirow[t]{2}{*}{ 3-D delta wings } & $\mathrm{SN} 1$ & 1.17 & 1 & 1 & 1 & 1 & 1.1 \\
\hline & SN2 & 1.37 & 1 & 1.11 & 1.12 & 1.14 & 1.15 \\
\hline \multirow{6}{*}{$\begin{array}{c}\text { Thin delta } \\
\text { wings }\end{array}$} & SN3 & 1 & 1 & 1.10 & 1 & 1 & 1 \\
\hline & SN4 & 1.30 & 1.10 & 1.11 & 1 & 1 & 1 \\
\hline & SN5 & 1 & 1 & 1 & 1 & 1 & 1 \\
\hline & SN6 & 1 & 1 & 1.10 & 1.10 & 1.14 & 1.15 \\
\hline & SN7 & 1 & 1.10 & 1.15 & 1.01 & 1 & 1 \\
\hline & SN8 & 1.26 & 1.10 & 1.11 & 1 & 1 & 1 \\
\hline $\begin{array}{l}\text { Active delta } \\
\text { wings }\end{array}$ & SN9 & 1.15 & 1.16 & 1.14 & 1 & 1.16 & 1.19 \\
\hline
\end{tabular}


In terms of rank, the fixed VG design and arrangement which gave the highest heat transfer enhancement was the staggered 3-D wing (SN2), with 37\% higher heat transfer compared to a plain fin stack. The performance of the punched-out staggered wings, SN4, and the inline punched-out wings, SN8, followed closely with enhancements of $30 \%$ and $26 \%$ respectively.

The common observations found in the top three wing designs and arrangements were their sufficiently wide spanwise spacing and relatively longer distance from the finstack leading edge. A wide spanwise spacing between the wings maintains strong and effective vortices by minimising the interference of neighbouring vortex paths, asobserved from comparing the different wing arrangement spacing in the current experiment. In terms of distance from the fin leading edge, although it is important that the VGtips are above the boundary layer, the current experiment results have shown that by increasing the VG distance from the leading edge results in increased cooling effects which provide significant contributions towards higher overall heat transfer enhancements. Apart from the wing design and arrangement considerations, the heat transfer enhancements were also observed to be higher for low $\mathrm{Re}_{\mathrm{H}}$ flows.With regard to flow conditions, the experimental data implies that the benefits of secondary mixing from longitudinal vortices are effectively obtained from a relatively structured, laminar flow compared to the flow conditions at higher $\mathrm{Re}_{\mathrm{H}}$.

The flow pressure loss across the test section, represented by the Darcy friction factor ratios, did not show asignificant increasein pressure drop that was expected due to theflow obstructions caused by the VGs.Forall the fixed VG designs (SN1 to SN8) in the experiment, the highest friction factor increase was $15 \%$ and on the average, the increase was only $4 \%$ compared to a plain fin stack.Contrary to the findings in the current experiment, previous reports have found increases in friction factors for a single delta wing VG in a channel to reach 50\% compared to a plain fin-stack under similar flow conditions. One reason for the relatively lower flow pressure loss in the current experiment was the high form drag contribution from the heat pipes which were present in both the plain and VG fin stacks.

The flow pressure loss issueispredicted to resurfaceif thedemand for higher heat transfer enhancementsare met by increasingthe number of VGs or their angles of 
attack and aspect ratios. A solution to address higher heat transfer enhancement demands without the flow pressure loss implication was explored with the active VG designs. In the current experiment, shape memory alloy VGs were stuck-on to the fin surfaces and provided the "active" features by responding to their respective temperature set-points. The active VG arrangement was carefully chosen based on the results of the fixed VG experiments and considerations of cost and maintenance in a full scale application. For the $60-\mathrm{W}$ heating power used in the fixed VG experiment, the fin temperatures were observed to be lower than the activation temperature of the active VGs. A 100-W heater supply was instead used to provide the required fin temperatures for activation within the $\mathrm{Re}_{\mathrm{H}}$ range of the experiment.

At their activation angles of $30^{\circ}$, the active VG array provided heat transfer enhancements of between 14 to $16 \%$ compared to when they are de-activated. The corresponding friction factor ratios were found to be in the range of 1 and 19\%. When de-activated, the VGs maintained a small angle of attack $\left(\alpha=5^{\circ}\right)$ which results in some heat transfer enhancements and flow pressure loss when compared to a plain fin stack. The heat transfer improvements from the de-activation angles were found to be between 1 and 25\%, for $\operatorname{Re}_{\mathrm{H}}=330,730$ and 960, compared to a plane fin stack.For the same de-activation angleand similarRe $\mathrm{H}_{\mathrm{H}}$ range, the increase in friction factors was found to be between 12 and $15 \%$.

The shape memory alloy VG fin stack experimental results confirmed that at high temperatures, when the delta wing was activated, the heat transfer coefficient would be higher than for a plain fin with equivalent pressure drop created by increasing airflow. At low temperatures, where the wing was deactivated, the desired reduction in pressure drop through the fin stack was also observed. With improvements in the shape memory training procedures, the de-activated angles can be further reduced and would result in larger differences in heat transfer enhancement effectsbetween the active and de-activated wing positions. In comparison with the fixed VGs, the active VGs were found to offer better thermal performance across the range of Reynolds numbers investigated.

\subsection{Numerical SimulationResults}


The CFD analysis provided useful data and information which could not be obtained from the experiment.

For selected VG designs and arrangements, contour plots representing temperature variations on the fin surfaces as a result of heat transfer enhancements are shown in Fig. 12. The average fin surface temperatures can be seen to be reduced by approximately $60 \%$ over that of the plain fin throughout the $\mathrm{Re}_{\mathrm{H}}$ range in the investigation. Based on the surface temperature information and the air temperature at specific streamwise locations, the heat transfer enhancements, calculated in terms of the local Nusselt number ratios, $\mathrm{Nu}_{\mathrm{x}} / \mathrm{Nu}_{\mathrm{o}}, \mathrm{x}$, are shown in Figs. 13-15.

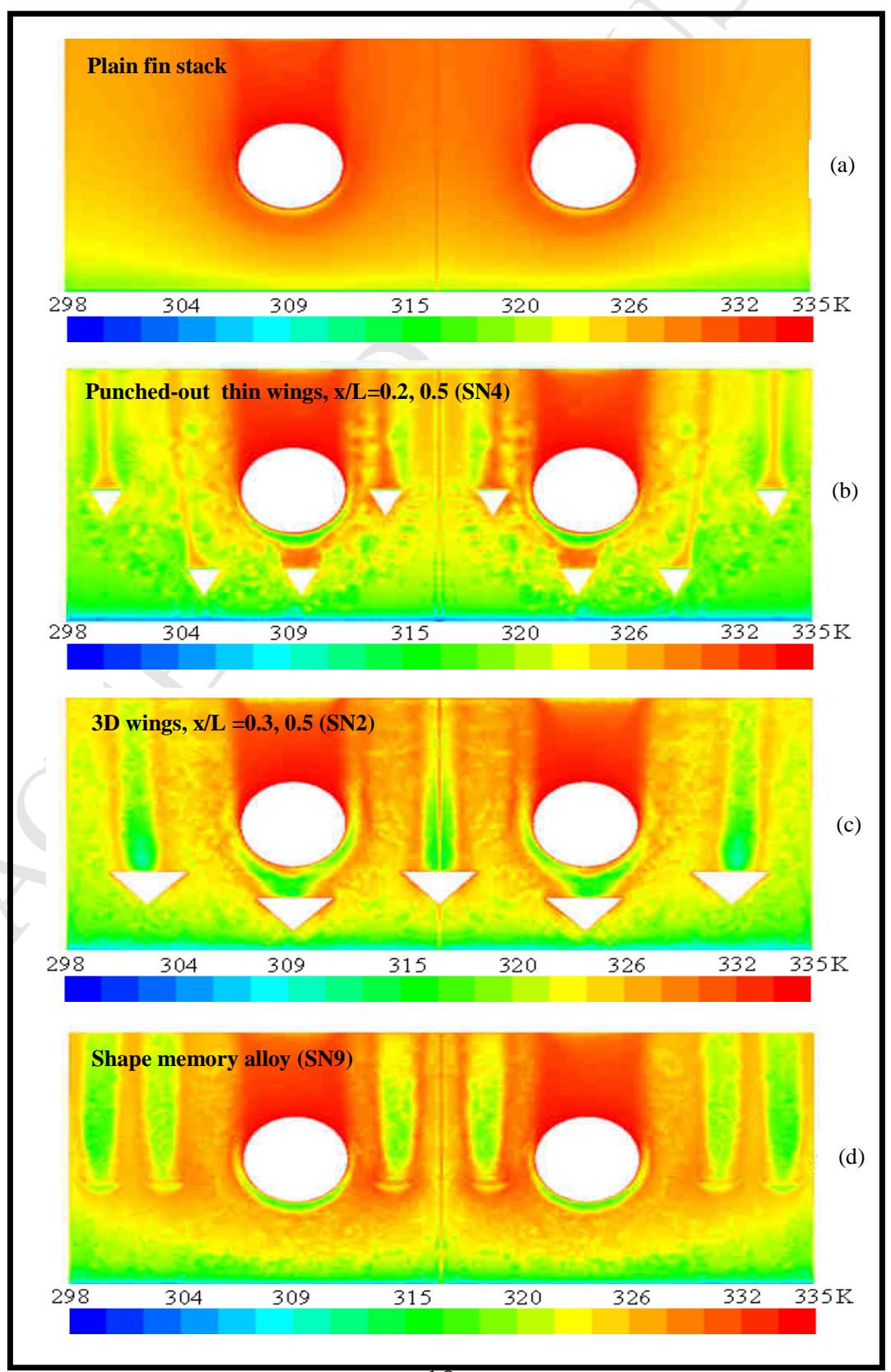

Figure 12: Temperature contouth for the bottom fin surfaces in the fin stack for a heat pipe temperature of $350 \mathrm{~K}$ and $\operatorname{Re}=\mathbf{3 0 0}$ 


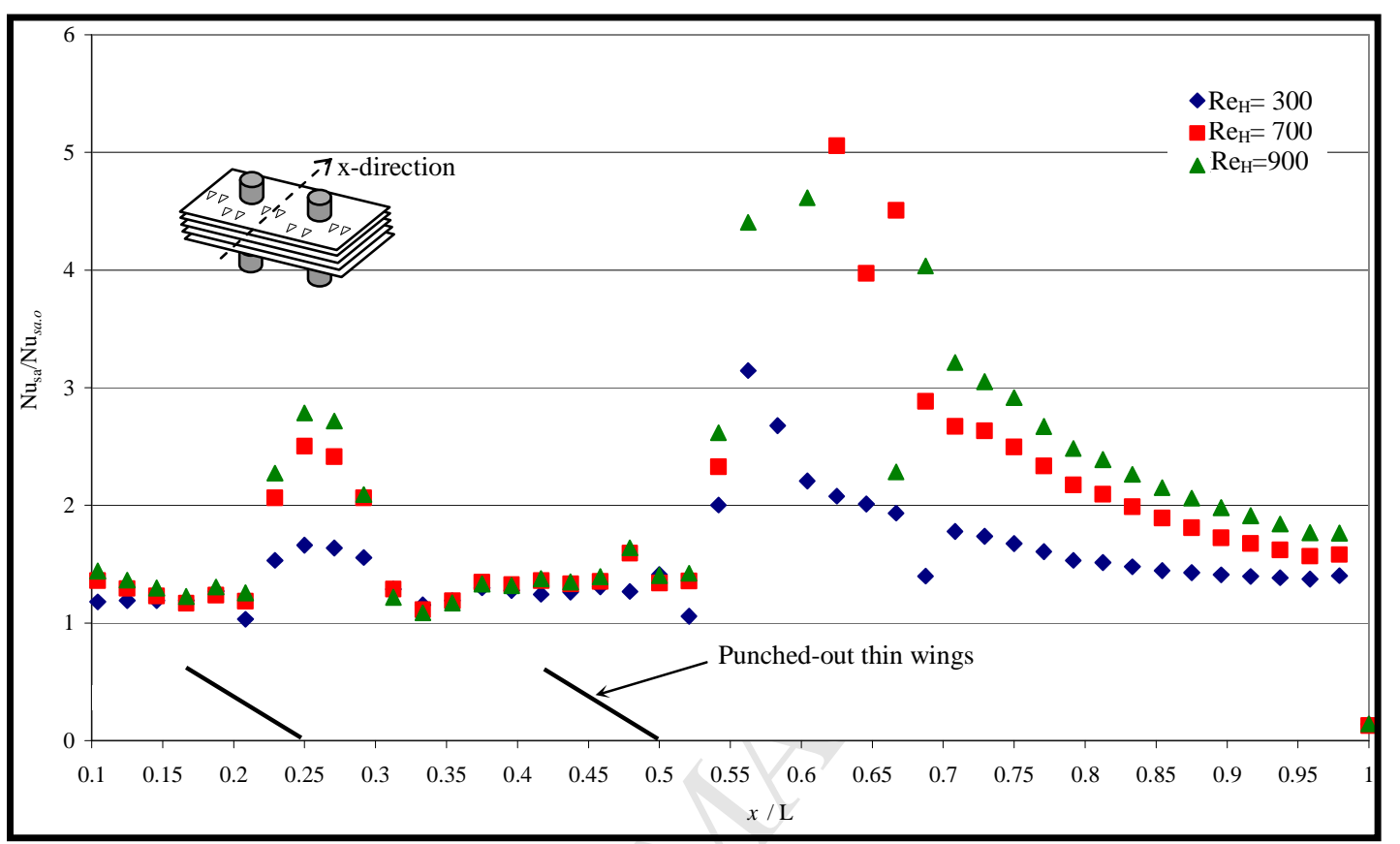

Figure 13: Streamwise Nusselt number ratio for the fin surface, along the centre of the fin stack width

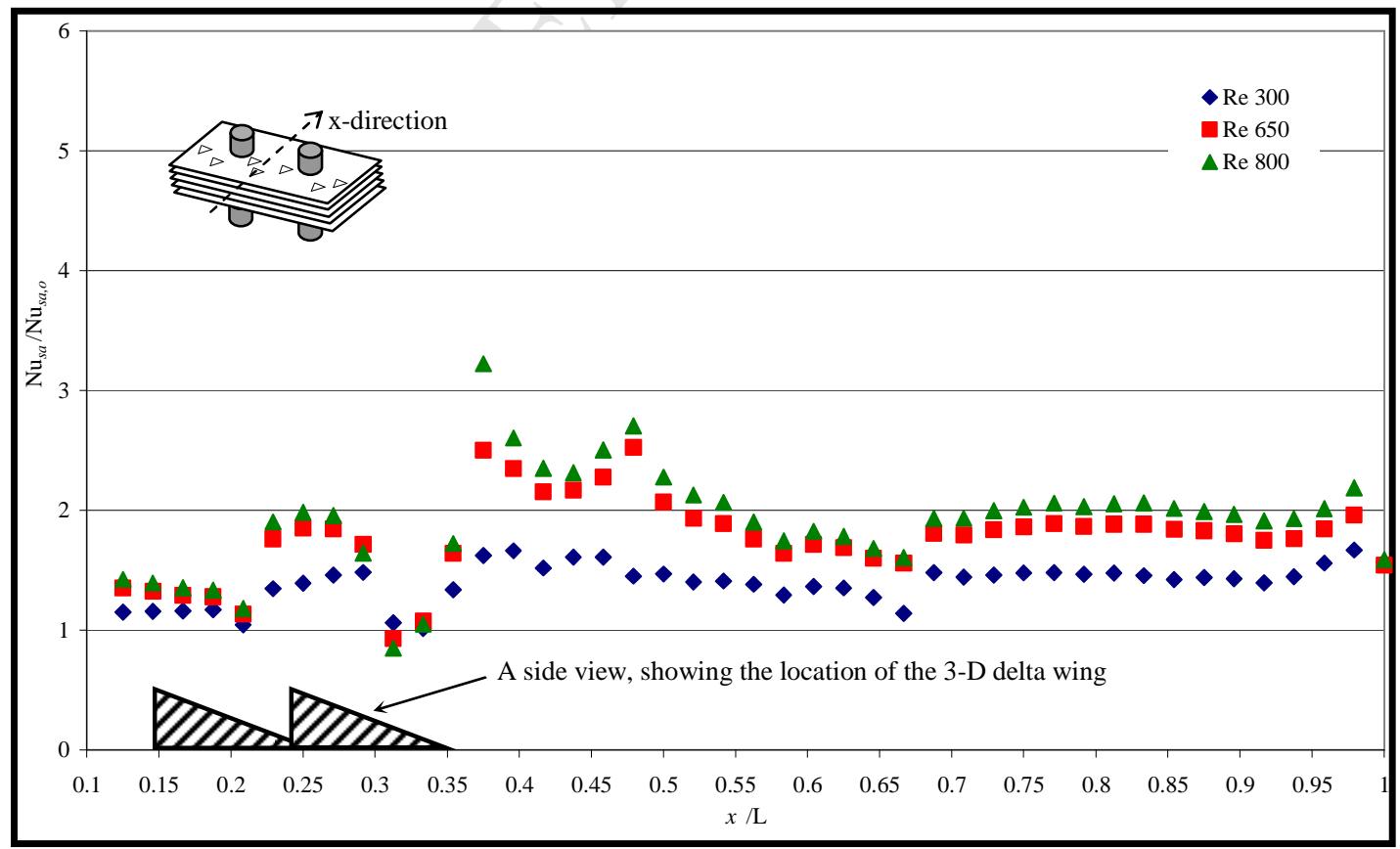

Figure 14: Streamwise Nusselt number ratio for the fin surface, along the centre of the fin stack width 


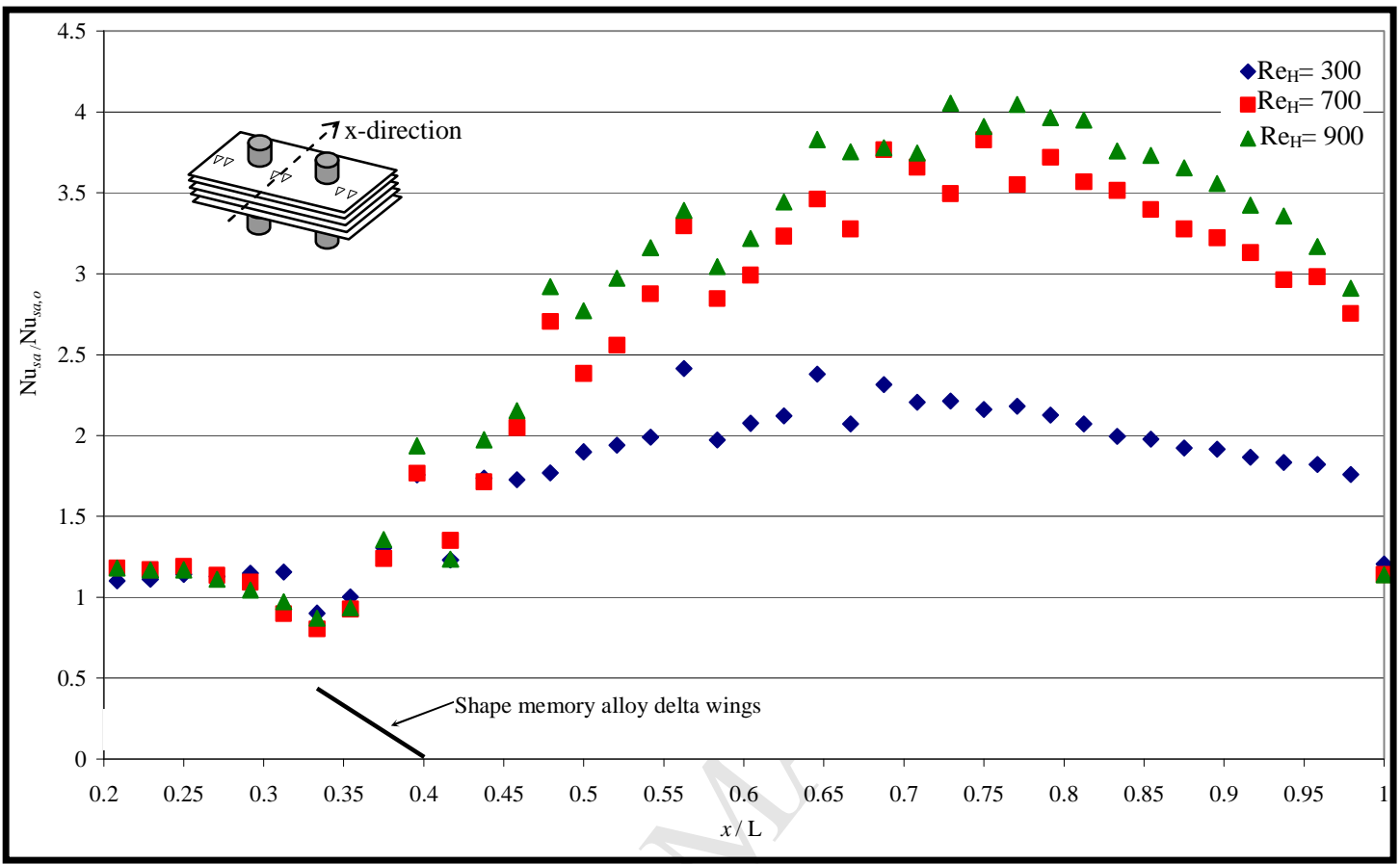

Figure 15: Streamwise Nusselt number ratio for the bottom fin surface, along the centre of the shape memory alloy fin stack width

In general, the numerical simulations gave a better understanding of the heat transfer enhancements on the fin surfaces due to the presence of VGs. The results from the current work were found to be consistent with the earlier findings of Fiebig et al. (1986, 1991, 1993), in terms of the downstream enhancement distribution. Biswas and Chattopadhyay (1992) had also shown similar streamwise heat transfer enhancement trends in their work on delta wings in channel flows. However, the presence of the heat pipe in the fin-stack channels (centred at $\mathrm{x} / \mathrm{L}=0.55$ ) of the current work seem to have elevated both the local and overall heat transfer enhancement effects of the delta wings compared to what was previously reported by Fiebig and Biswas. Local heat transfer enhancement effects $\left(\mathrm{Nu}_{\mathrm{x}} / \mathrm{Nu}_{\mathrm{x}, \mathrm{o}}\right)$ reached as high as $300 \%$ for the active VGs, $270 \%$ for $3-D$ fixed wings and $400 \%$ for staggered thin fixed wingscompared to plain fins at downstream locations which were close to the heat pipe. 
Higher local heat transfer enhancements were observed for the shape memory alloy VGs compared to the other fin-stacks. The inline arrangement of the active VGs, in the presence of the heat pipe, generated strong vortices at a location of approximately two chord lengths downstream of the VG array. The enhancement effects then gradually decreased towards the tail-end of the fin-stack. For the fixed 3-D and thin wing fin stacks, the local enhancement effects experienced a slight increase after the first VGrow and were further elevated after the second row, which was within close proximity to the heat pipes.

In terms of the overall heat transfer enhancement and friction effects, the ratios, $\mathrm{Q}_{\mathrm{Q}} \mathrm{Q}_{\mathrm{o}}$ and $\mathrm{f} / \mathrm{f}_{o}$ were calculated using Equations (1) and (2) and presented in the following tables.

Table 4: Overall heat transfer enhancement effects from VG compared to plain fin stacks

\begin{tabular}{|l|c|c|c|}
\hline \multicolumn{1}{|c|}{$\mathbf{Q} / \mathbf{Q}_{\boldsymbol{o}}$} & Re 300 & Re 700 & Re 900 \\
\hline Active delta-wings & 1.21 & 1.27 & 1.38 \\
\hline Fixed, 3-D delta wings & 1.10 & 1.11 & 1.07 \\
\hline Fixed, thin delta-wings & 1.12 & 1.12 & 1.17 \\
\hline
\end{tabular}

Table 5: Overall friction factors from VG compared to plain fin stacks

\begin{tabular}{|l|l|l|l|}
\hline \multicolumn{1}{|c|}{$\boldsymbol{f l f}, \boldsymbol{o}$} & Re 300 & Re 700 & Re 900 \\
\hline Active delta-wings & 1.20 & 1.12 & 1.06 \\
\hline Fixed, 3-D delta wings & 1.06 & 0.97 & 0.93 \\
\hline Fixed, thin delta-wings & 1.10 & 1.05 & 1.03 \\
\hline
\end{tabular}

The average overall heat transfer enhancements and friction factors for the CFD simulations were compared and used as an early validation exercise. The CFD estimates were found to be fairly close to the experimental results for the range of Reynolds numbers in the current work considering the experimental uncertainties and assumptions made in applying the boundary conditions for the CFD model.The average difference in heat transfer enhancements and friction factors for the active, thin and 3-D delta wings were found to be 10, 11 and $7 \%$ (heat transfer enhancements) and 10, 13, $6 \%$ (friction factors) respectively.

The shape memory alloy VGs were found, in the CFD simulations, to give the highest overall enhancements followed by the fixed, thin and 3-D wing arrangements. The 
CFD data has also estimated insignificant differences in the friction factor for the VG and plain fin-stacks. Similar friction factor results were obtained in the experiments and are believed to be due to the dominance of the form drag contributions from the heat pipes.

The close agreement between the experimental and CFD data is encouraging as it allows CFD to provide an alternative analysis of VG fin-stacks for the heat pipe condenser unit.

\subsection{Conclusions}

An investigation into improving the thermal performance of a heat pipe condenser finstack with the use of delta wing vortex generators were successfully carried out. The delta wing designs were selected based on previous findings of the thermal performance of a single wing located on either a flat plate or in a channel for various flow conditions. The investigation was also extended to include the use of novel,active delta wing designs made from shape memory alloys.

The fixed delta wings were found to provide heat transfer enhancements as high as $37 \%$ and a maximum increase in flow pressure loss of $15 \%$ compared to plain fin surfaces. A staggered arrangement of 3-D wings with an aspect ratio of four and an angle of attack of $14^{\circ}$ gave the highest enhancement effects followed by a staggered and an in-line arrangement of thin, punched-out wings. However, when the wing to fin surface area ratios were taken into account, the lesser number wings in the in-line arrangement gave higher specific heat transfer enhancements compared to the 3-D and staggered thin wing arrangements. The sufficient wing spacing and distance from the fin stack leading edge were among the factors which were featured in the designs and arrangements that gave favourable thermal performance. As for the active delta wings, although the heat transfer enhancements provided were not as high as the fixed delta wings, they offer an additional featurewhich is the ability to manage flow pressure losses. This is especially useful when more VGs or VGs with higher angles of attack or aspect ratios are required to meet higher enhancement demands. 
The findings from the current research offer a solution to improve the thermal performance of heat pipe systems through the use of delta wing vortex generators. The novel, active vortex generatorsmade from shape memory alloyscontributed towards heat transfer enhancements by manipulating the delta wing geometrical features without the usual issue of high flow pressure losses. Considering the preliminary stage of development in which the active delta wing designs are currently in, there remains ample room for improvements in future development work to overcome concerns of manufacturing, material costs and reliability.

\subsection{Acknowledgement}

The authors would like to thank Ben Shaw of Thermacore Europe for his work within the test laboratory and on the test facility during this investigation, and James Mee from the University of Liverpool who contributed in the CFD evaluation of the fin stack heat transfer enhancement.

\subsection{Reference}

Aris, M.S. I. Owen and C.J. Sutcliffe (2007).“The application of shape memory alloy as vortex generators and flow control devices for enhanced convective heattransfer." Proceedings of the Fifth Joint ASME/JSME Fluids Engineering Conference, ASME, San Diego, Ca:Error! Hyperlink reference not valid.

Aris, M. S., Owen, I., Sutcliffe, C.J. (2008). "The Development of Active Flow Control Devices from Shape Memory Alloys for the Convective Cooling of Heated Surfaces." Proceedings of IMECE2008 2008 ASME International Mechanical Engineering Congress and Exposition: IMECE2008-68691.

Biswas, G. and H. Chattopadhyay (1992). "Heat transfer in a channel with built-in wing-type vortex generators." International Journal of Heat and Mass Transfer35(4): 803-814.

Edwards,F. J. and Alker, C.J.R. (1974). "The Improvement of forced convection surface heat transfer using surface protrusions in the form of (a) cubes and (b) vortex generators." Proceedings from the 5th International Heat Transfer Conference 244-248.

ElSherbini, A. I. and Jacobi, A. M. (2002). "The thermal-hydraulic impact of deltawing vortex generators on the performance of a plain-fin-and-tube heat exchanger." HVAC and R Research8(4): 357-370.

Fiebig, M. (1986). "Wing type vortex generators for heat transfer enhancement." Proceedings from the 8th International Heat Transfer Conference6: 29092913. 
Fiebig, M., Kallweit, P.,Mitra, N. and Tiggelbeck, S. (1991). "Heat transfer enhancement and drag by longitudinal vortex generators in channel flow." Experimental Thermal and Fluid Science4(1): 103-114.

Fiebig, M., Valencia, A. and Mitra, N.K. (1993). "Wing type vortex generators for fin and tube heat exchangers." Experimental Thermal and Fluid Science7: 287295.

Gentry, M. C. and Jacobi, A. M. (2002). "Heat transfer enhancement by delta-winggenerated tip vortices in flat-plate and developing channel flows." Journal of Heat Transfer124(6): 1158-1168.

Gentry, M. C. (1998). Heat transfer enhancement using tip and junction vortices. Mechanical Engineering. Urbana-champaign, University of Illinois. PhD: 197.

Jacobi, A. M. and Shah, R. K. (1995). "Heat transfer surface enhancement through the use of longitudinal vortices: A review of recent progress." Experimental Thermal and Fluid Science 11(3): 295-309.

Kline S J and McClintock F A, 1953, "Describing Uncertainties in Single Sample Experiments", Mechanical Engineering75: 3.

Lahoz, R., Gracia-Villa, L. and Puertolas, J.A. (2002). "Training of the two-way shape memory effect by bending in NiTi alloys." Journal of Engineering Materials and Technology 124: 397-401.

Liou, T.M., Chen, C.C. and Tsai, T.W. (2000). "Heat transfer and fluid flow in a square duct with 12 different shaped vortex generators." Journal of Heat Transfer122(2): 327-335.

Pauley, W. R.and Eaton, J. K. (1994). "The effect of embedded longitudinal vortex arrays on turbulent boundary layer heat transfer." Journal of Heat Transfer116(4): 871-879.

Sommers, A. D. and Jacobi, A. M. (2005). "Air-side heat transfer enhancement of a refrigerator evaporator using vortex generation." International Journal of Refrigeration 28(7): 1006-1017.

\section{Webpage reference:}

Memry Metalle GmbH. (2009). "http://www.memory-metalle.de/.", Retrieved $21^{\text {st }}$ July, 2009

\subsection{Nomencleature}

\section{$\underline{\text { Symbol }}$}

Units or definition

A

A

at $\%$

b

$\mathrm{Cp}$

c
Area

Austenite phase

Atomic percentage

Sample/wing width

Constant specific heat

Sample height/chord length $\mathrm{mm}^{2}$

$\mathrm{mm}$

$\mathrm{kJ} / \mathrm{kgK}$

$\mathrm{mm}$ 


\section{$f$}

$\mathrm{H}$

$h$

j

$k$

$L$

M

im

$\mathrm{Nu}$

$P$

$Q$

$\operatorname{Re}_{\mathrm{H}}$

$S$

$\mathrm{T}$

$\mathrm{t}$

U

V

W

W

$X$

Y

\section{$\underline{\text { Sub-scripts }}$}

avg

bm
Apparent friction factor

$$
\frac{\Delta \mathrm{P} \cdot \mathrm{H}}{L \frac{1}{2} \rho \mathrm{V}_{\text {avg }}{ }^{2}}
$$

Channel height

$\mathrm{mm}$

Heat transfer coefficient

$\frac{W}{m^{2} K}$

Colburn-j factor

Thermal conductivity

Test section length

$\frac{\mathrm{Nu}}{\operatorname{Re} \operatorname{Pr}^{1 / 3}}$

$\frac{W}{m K}$

$\mathrm{mm}$

Martensite phase

Mass flow rate

$\mathrm{kg} / \mathrm{s}$

Nusselt number

h $\mathrm{H}$

Pressure

$\mathrm{Pa}$

Rate of heat transfer

W

Reynolds number based on channel height

$\frac{\rho V_{\text {avg }} H}{\mu}$

Wing/sample spacing

$\mathrm{mm}$

Temperature

${ }^{\circ} \mathrm{C}$

Thickness

$\mathrm{mm}$

Air velocity

$\mathrm{m} / \mathrm{s}$

Velocity

$\mathrm{m} / \mathrm{s}$

Test section width

$\mathrm{mm}$

Delta wing array spacing

$\mathrm{mm}$

Streamwise spacing

$\mathrm{mm}$

Spanwise spacing

average

Bulk mean temperature, $\left(\mathrm{T}_{\text {air,in }}+\mathrm{T}_{\text {air,out }}\right) / 2$ 


$\begin{array}{ll}f & \text { Finish } \\ H & \text { Channel height } \\ L & \text { Test section length } \\ \mathrm{o} & \text { Plain surface } \\ p & \text { Permanent deformation } \\ s & \text { Start } \\ \mathrm{s} & \text { surface } \\ s a & \text { Spanwise average } \\ t w & \text { Two-way angular response } \\ V G & \text { Vortex generator } \\ \infty & \text { Free stream }\end{array}$

\section{Greek symbols}

$\alpha$

$\Lambda$

$\Delta$

$\rho$

$\sigma$

$\mu$

$\theta$
Angle of attack

Aspect ratio

$2 b / c$

Difference

Fluid density

Stress

$\mathrm{kg} / \mathrm{m}^{3}$

$\mathrm{N} / \mathrm{m}^{2}$

Fluid viscosity

Bending angle
$\mathrm{N} / \mathrm{s}$

o 